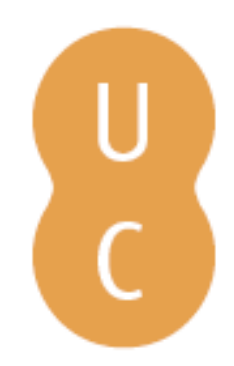

\title{
pommalina
}

\section{Front's dynamics of quasi-infinite grassland fires}

Autor(es): $\quad$ Frangieh, Nicolas; Accary, Gilbert; Méradji, Sofiane; Morvan, Dominique

Publicado por: Imprensa da Universidade de Coimbra

URL

persistente: URI:http://hdl.handle.net/10316.2/44630

DOI: $\quad$ DOI:https://doi.org/10.14195/978-989-26-16-506_113

Accessed : $\quad$ 26-Apr-2023 01:25:51

A navegação consulta e descarregamento dos títulos inseridos nas Bibliotecas Digitais UC Digitalis, UC Pombalina e UC Impactum, pressupõem a aceitação plena e sem reservas dos Termos e Condições de Uso destas Bibliotecas Digitais, disponíveis em https://digitalis.uc.pt/pt-pt/termos.

Conforme exposto nos referidos Termos e Condições de Uso, o descarregamento de títulos de acesso restrito requer uma licença válida de autorização devendo o utilizador aceder ao(s) documento(s) a partir de um endereço de IP da instituição detentora da supramencionada licença.

Ao utilizador é apenas permitido o descarregamento para uso pessoal, pelo que o emprego do(s) título(s) descarregado(s) para outro fim, designadamente comercial, carece de autorização do respetivo autor ou editor da obra.

Na medida em que todas as obras da UC Digitalis se encontram protegidas pelo Código do Direito de Autor e Direitos Conexos e demais legislação aplicável, toda a cópia, parcial ou total, deste documento, nos casos em que é legalmente admitida, deverá conter ou fazer-se acompanhar por este aviso. 


\section{ADVANCES IN}

\section{FOREST FIRE RESEARCH}

\section{8}

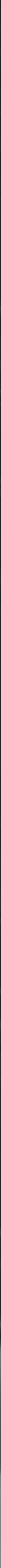




\title{
Front's dynamics of quasi-infinite grassland fires
}

\author{
Nicolas Frangieh $^{* 1}$; Gilbert Accary ${ }^{2}$; Sofiane Méradji ${ }^{3}$; Dominique Morvan ${ }^{1}$ \\ ${ }^{1}$ Aix-Marseille Univ, CNRS, Centrale Marseille, M2P2, Marseille, France, \\ \{nicolas.frangieh1@hotmail.com*,dominique.morvan@univ-amu.fr\} \\ ${ }^{2}$ Scientific Research Center in Engineering, Lebanese University, Lebanon, \{gaccary@ul.edu.lb\} \\ ${ }^{3}$ IMATH, EA 2134, Toulon University, France, \{meradji@univ-tln.fr\}
}

\begin{abstract}
Numerical simulations of grassland fires were carried out to study the effects of the wind speed on the dynamics of the fire front. This study was performed using a detailed physical model based on a multiphase formulation, consisting in solving the balance equations (mass, momentum, energy ...) governing the behavior of the coupled system formed by the vegetation layer and the surrounding atmosphere. The objective of this study is to focus on the 3D interactions between a quasi-infinite fire front propagating through a homogeneous vegetation layer (a grassland) and an atmospheric boundary layer flow representing an idealized wind flow. The behavior of a surface fire results from the competition between the buoyant force of the thermal plume and the inertial force of the wind. In 3D, the interaction between these two forces is at the origin of the structuration of the fire front as a succession of peaks and troughs that modify the flames dynamics in a manner different to what can be observed in a simplified 2D assumption. To reproduce a quasi-infinite fire front, the numerical simulations were carried out using periodic boundary conditions along the two lateral sides of the computational domain. The numerical results highlights the 3D structuration of the fire both vertically and horizontally, and the significant effect of an increase of the wind velocity on the rate of spread (ROS) and on the fire intensity. Results also show that the correlation between Froude's number (based on the fire-front structures characteristic-wavelength) and Byram's number is the same at small scale (litter fires) and at large scale (grassland fires).
\end{abstract}

Keywords: Fire dynamics, Physical model, Numerical simulation, Grassland fire

\section{Introduction}

From a physical and mathematical point of view, a wildfire is a multiscale and complex problem; for this reason, most of operational tools predicting wildfires behavior, such as PHOENIX (Tolhurst et al, 2008) in Australia and FARSITE in the US (Finney, 1998), are based on statistical or semiempirical approaches, namely the MK5 model (McArthur, 1967) in Australia and the BEHAVE model in the US (Rothermel, 1972). However, in many situations, the quality of the predictions compared to real observations on well documented fire can be qualified at least as poor (Hanson et al, 2000). The limitations highlighted in empirical or semi-empirical models are mainly due to the fact that the predictions outside the data-set range used for the model statistics are generally subjected to great uncertainties and generally not suitable. Consequently, other approaches have been proposed to improve the understanding of the physical processes governing the behavior of fires. This alternative class of fire models is based on more or less realistic description of the physical phenomena governing the heat transfer between the fire front and the vegetation (Sullivan, 2009). A fully physical model addresses the problem of fire spread by analyzing its behavior through its physicochemical aspects (Grishin and Albini, 1997, Mell et al, 2007). This approach minimizes the need of using an empirical parameterization, even if, compared to empirical and semi-empirical models, it needs bigger computational resources, it is also more promising in the understanding of the physics of fires (Mell et al, 2007, Linn and Cunningham, 2005, Morvan et al, 2009). The fully physical approach has also a great potential in the management of fire hazard in wildland-urban interfaces, such as the dimensioning of a fuel break, the evaluation of heat flux on a target located inside the WUI, the interaction between two fire fronts (Morvan, 2015, Mell et al, 2010)

Advances in Forest Fire Research 2018 - Page 1024 
The 3D model used in this study (FireStar3D) is based on a multiphase formulation and solves the conservation equations of the coupled system formed by the vegetation and the surrounding gaseous medium (Grishin and Albini, 1997, Morvan et al, 2018). The predictive potential of FireStar3D model was tested at a small scale in the case of litter fires (Morvan et al, 2018), as well as at a larger scale in the case of grassland fires (Frangieh et al, 2018) that have been extensively studied experimentally (Cheney et al, 1998). In this study, the fire-front dynamics and spread through a homogeneous grassland is analyzed, for different wind speeds, in terms of rate of fire spread, fire intensity, and characteristic-wavelength of the fire-front structures. The results are compared with data collected during experimental campaigns and predictions from semi-empirical and physical models.

\section{Modeling and Numerical Method}

The mathematical model is based on a multiphase formulation, it consists in a first step of averaging the conservation equations (mass, momentum, energy ...) governing the behavior of the coupled system formed by the vegetation and the surrounding atmosphere inside elementary control volumes including both the solid phase (the vegetation) and the gaseous phase. This results in the introduction of source/sink terms on the right hand side of the equations, representing the contributions of the interaction terms (exchanges of mass, drag, heat flux ...) between the gaseous phase and the vegetation. The details of the model have been widely presented in previous publications, we invite the reader to consult Grishin and Albini, 1997, and Morvan et al, 2009, for more information.

The model consists of two parts that are solved on two distinct grids. The first part consists of the equations of a reacting turbulent flow in the gaseous phase composed as a mixture of fresh air with the gaseous products resulting from pyrolysis and combustion. The second part consists of the equations governing the state and the composition of the solid phase.

The gaseous phase model consists in the conservation equations of mass, momentum, energy, and chemical species $\left(\mathrm{O}_{2}, \mathrm{~N}_{2}, \mathrm{CO}, \mathrm{CO}_{2}\right.$, and $\left.\mathrm{H}_{2} \mathrm{O}\right)$ filtered using either a LES approach (Sagaut, 2006) or an Unsteady RANS approach (URANS) with Favre average formulation (Cox, 1995). Both approaches are available, but the LES model was used in this study. The closure of the averaged conservation equations is based on the concept of eddy viscosity (Sagaut, 2006) obtained from an evaluation of the turbulent kinetic energy. The temperature dependence of the gas-mixture enthalpy is based on CHEMKIN thermodynamic tables (Kee et al, 1992). A combustion model based on Eddy Dissipation Concept (EDC) (Cox, 1995) is used to evaluate the combustion rate occurring in the gaseous phase. Finally, the field of soot volume-fraction in the gas mixture is calculated by solving a transport equation including a thermophoretic contribution in the convective term and taking into consideration soot oxidation (Syed et al, 1991).

During the thermal degradation of the solid phase, the composition of the fuel particles representing the vegetation is represented as a mixture of dry material (generic term for a mixing of cellulose, hemicellulose, and lignin), charcoal, moisture, and residual ashes. For each solid particle, the model consists in the conservation equations of the mass fractions of water, of dry material, of charcoal, as well as of the total mass of the solid particle, its volume fraction and its temperature (Grishin and Albini, 1997, Morvan, 2015, Morvan et al, 2018). The degradation of the vegetation is governed by three temperature-dependent mechanisms: drying, pyrolysis, and charcoal combustion. The pyrolysis process starts once the drying process is completed and charcoal combustion starts once the pyrolysis process is achieved.

The interaction between the gaseous phase and the solid one obtained through coupling terms that appear in both parts of the model. The coupling in the momentum and turbulence equations is obtained by adding aerodynamic drag terms (Morvan et al, 2018) that include a drag coefficient (evaluated empirically, equal to 0.15 in the present study) multiplied by a reference surface, defined as the Leaf Area Density (LAD). Heat transfer between the gas mixture and the solid fuel is based on empirical 
correlations for convective transfer (Incropera and DeWitt, 1996), and on the resolution of the radiative transfer equation (Modest, 2003) that accounts for the presence of soot in the flaming zone and for the presence of hot particles in the vegetation layer (embers) (Grishin and Albini, 1997). Finally, mass transfer from the solid phase to the gaseous phase is obtained by adding source/sink terms in the mass conservation equations of both phases.

The Radiative Transport Equation (RTE) is solved using a Discrete Ordinate Method (DOM), consisting in solving the radiation-intensity equation in a finite number of directions (Modest, 2003). This set of discrete contributions is then integrated using a numerical Gaussian quadrature rule (a S8 method is used here) for the calculation of the total irradiance. The radiative transfer equation accounts for gas-soot mixture absorption of radiative intensity depending on the amounts of combustion products $\left(\mathrm{CO}_{2}\right.$ and $\left.\mathrm{H}_{2} \mathrm{O}\right)$, on the gas mixture temperature, and of the soot volume fraction (Kaplan et al, 1994).

\section{Grassland Fire Configuration}

To reproduce the conditions similar to those encountered in the case of a quasi-infinite fire front and to avoid the border effects induced by a finite-length ignition line on the fire behavior (Cheney and Gould, 1995, Linn et al, 2012), the numerical simulations were carried out using periodic boundary conditions along the two lateral sides of the computational domain (Canfield et al, 2014), as shown in Fig. 1. The length $L$ of the computational domain was increased with the wind speed from $120 \mathrm{~m}$ up to $600 \mathrm{~m}$ in order to reach a steady rate of spread, while the fire front is still far enough from the end of the domain. The homogeneous vegetation layer is located at $20 \mathrm{~m}$ from the domain inlet and has the following main properties (Linn and Cunningham, 2005, Morvan et al, 2009): vegetation height $\delta=0.7 \mathrm{~m}$, volume-fraction $\alpha=0.002$, surface-to-volume ratio $\sigma=4000 \mathrm{~m}^{-1}$, moisture content $M=$ $5 \%$, dry material density $\rho=500 \mathrm{~kg} \cdot \mathrm{m}^{-3}$, solid-fuel particles are assumed to have cylindrical shape and to behave as a black body. The simulations were carried out for seven values of the $10-\mathrm{m}$ open wind speed: $1,3,5,8,10,12$, and $16 \mathrm{~m} / \mathrm{s}$. These velocities were measured at the domain inlet, $10 \mathrm{~m}$ above ground.

For all wind speeds, the same mesh size was used in the $y-z$ plane: for the solid phase a uniform grid with $(\Delta y, \Delta z)=(0.25 \mathrm{~m}, 0.035 \mathrm{~m})$ was used, while for the fluid phase a uniform grid with $(\Delta y$, $\Delta z)=(0.5 \mathrm{~m}, 0.07 \mathrm{~m})$ was used within the vegetation before being gradually coarsened in the vertical direction. Both the solid-phase grid and the fluid-phase one were characterized by cells sizes below the extinction length scale (Morvan et al, 2009) within the vegetation given by $4 / \alpha \sigma$ and equal to 0.5 $\mathrm{m}$ in our case. This value is not to be exceeded in order to avoid fire extinction, especially in the case radiation-dominated fire propagation (i.e. when the wind speed is low). A uniform mesh was used in the $x$ direction but its size was increased with the wind speed: for the solid phase, the mesh size varied from $\Delta x=0.25 \mathrm{~m}$ for $U=1 \mathrm{~m} . \mathrm{s}^{-1}$ up to $\Delta x=0.5 \mathrm{~m}$ for $U=16 \mathrm{~m} \cdot \mathrm{s}^{-1}$, the mesh size of the fluid phase was twice that of the solid one.

Before activating the burner, the hydrodynamic module of the code was run long enough until reaching a statistically quasi-steady state. During this purely dynamic phase, homogeneous Neumann boundary conditions were imposed at the top, inlet, and outlet boundaries of the computational domain for all primary variables of the problem except for $y$ and $z$-velocity components that were set to zero. In addition, a negative pressure gradient is applied in the wind direction $(O x)$; this pressure gradient was automatically adjusted during this dynamic phase to obtain the desired 10-m open wind speed. This procedure allowed collecting the turbulent fields at the open boundaries, and these fields were then used during the burning phase, in particular for the management of the entering turbulent fluxes. Once the flow had reached a statistically-steady state, the burner was activated along an ignition line by injecting $\mathrm{CO}$ gas at $1600 \mathrm{~K}$ in the burning zone from the bottom boundary of the domain. The burner was activated during $25 \mathrm{~s}$ (at most) or until the consumption of a solid-fuel mass equal to that 
available above the burning area (i.e. contained in a volume of $2 \times 100 \times \delta \mathrm{m}^{3}$ ). More details about the ignition procedure are given in (Frangieh et al, 2018).

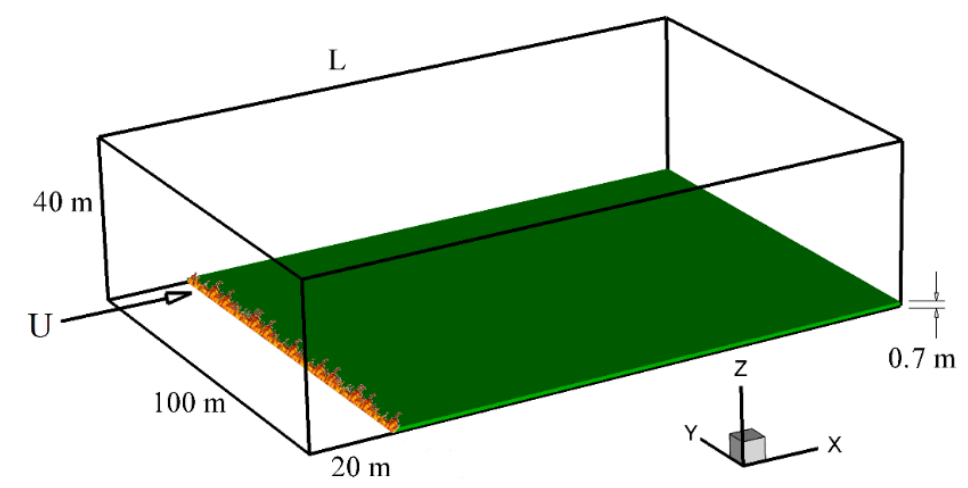

Figure 1 - Perspective view showing the dimensions of the computational domain and of the vegetation cover, the ignition line is $2 \mathrm{~m}$ wide.

The results presented in this study were obtained using a variable time step strategy based on the truncation-error control, with time step values varying between $0.001 \mathrm{~s}$ and $0.01 \mathrm{~s}$. At each time step, the solution is assumed to be obtained when the residuals of all conservation equations had reached $10^{-4}$ in normalized form. As a rough estimation of the computational cost, the simulation of $1 \mathrm{~s}$ of fire propagation required about $7 \mathrm{~h}$ of $\mathrm{CPU}$ time on a 24 -cores node.

\section{Numerical Results}

The description of the results is limited to local three-dimensionality of quasi-infinite grassland fire and its effect on fire line propagation with a specific focus on rate of spread, fire intensity, fire regime, and characteristic-wavelength of the fire-front structures for different wind speeds.

To understand the effect of the wind speed on the flame structure and more generally on the dynamics of fire, 3D views of the fire propagation obtained for $U_{10}=1 \mathrm{~m} / \mathrm{s}$ and $10 \mathrm{~m} / \mathrm{s}$ are shown in Fig. 2. For a small value of the wind speed $\left(U_{10}=1 \mathrm{~m} / \mathrm{s}\right)$, the flame plumes rise is not noticeably affected by the action of the cross wind. In this case the fire front can be assimilated to an obstacle, and the air flow is deflected vertically by the plume. On the other hand, figure 2 shows how larger value of wind speed $\left(\mathrm{U}_{10}=10 \mathrm{~m} / \mathrm{s}\right)$ affects more significantly the rise of the flame plumes by crossing the fire front and pushing the hot gases toward the unburned vegetation. We can also notice that the wind speed increases significantly the depth of the fire front.

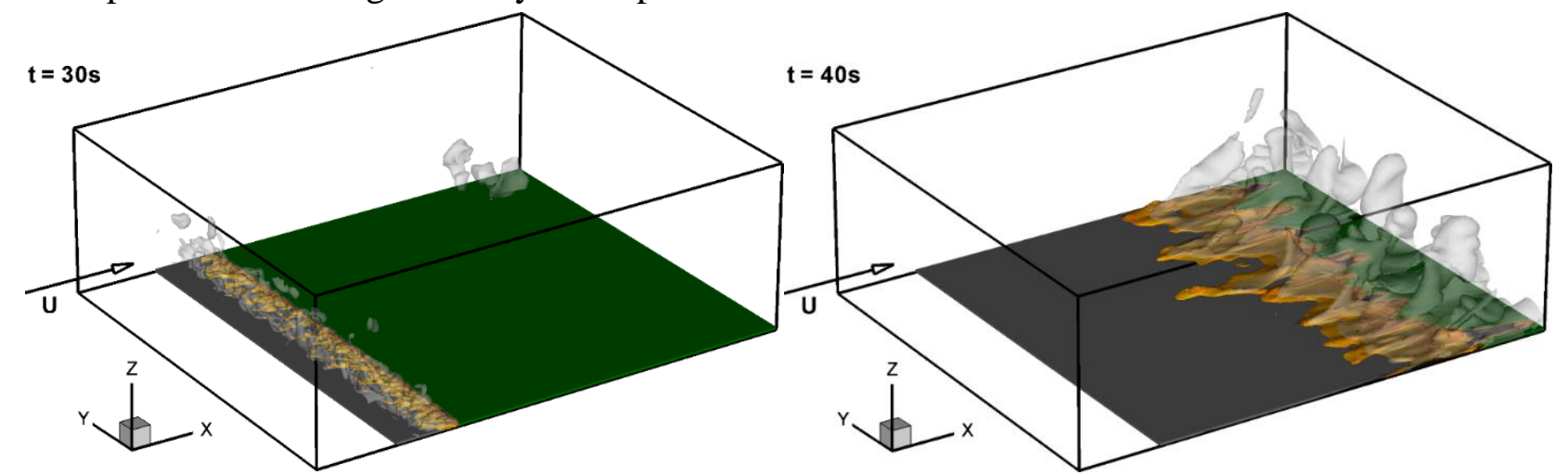

Figure $2-3 D$ view of an isovalue surface of the soot volume fraction $\left(10^{-6}\right)$ colored by the gas temperature (in yellow) and an isovalue surface of the water mass fraction $\left(10^{-3}\right)$ (in grey with $50 \%$ of transparency) for $U_{10}=1 \mathrm{~m} / \mathrm{s}($ top) and $U_{10}=10 \mathrm{~m} / \mathrm{s}$ (bottom), showing the effect of wind speed on the fire dynamics.

These phenomena are further illustrated by Fig. 3, where we notice that for a low wind speed, fresh air is aspirated from the vicinity of the fire front supplying the thermal plume; this regime is often 
referred to as "plume dominated fires". These results highlight the capability of the code to reproduce the backflow generated by the fire front on the leeward direction. For stronger wind conditions, the structure of the air flow is less affected by the fire front as shown in Fig. 3 (bottom), and this effect is limited to the local acceleration of the flow (resulting from a local expansion of the gas) in the plume; this regime is often referred to as "wind-driven fires". The streamlines show clearly the possibility for the inlet air flow to cross the fire front that must be structured vertically in peaks and troughs (Beer, 1991). The reproduction of this configuration is not possible in $2 \mathrm{D}$, because in $2 \mathrm{D}$ the fire front represents a uniform thermal barrier.

The effect of the wind speed on the flow structures is shown in Fig. 4 through the $Q$-criterion. This invariant of velocity gradient tensor represents the balance between the rotation and strain rates and is an appropriate tool for the visualization of coherent structures in a turbulent flow (Hunt et al, 1988). Figure 4 clearly shows that the assumption of a homogeneous plane made for the fire front in the radiant panel theory is not valid, the fire front is structured as a succession of peaks and troughs allowing for the air flow to find a way across it (Beer, 1991). This heterogeneity of the flame and the flow structure along the transverse direction, which is a great demonstration of 3D effects in a fire, affects a lot the propagation of the fire, as it has been clearly demonstrated experimentally at small scale (Finney et al, 2015) and numerically at larger scale (Linn et al, 2012).
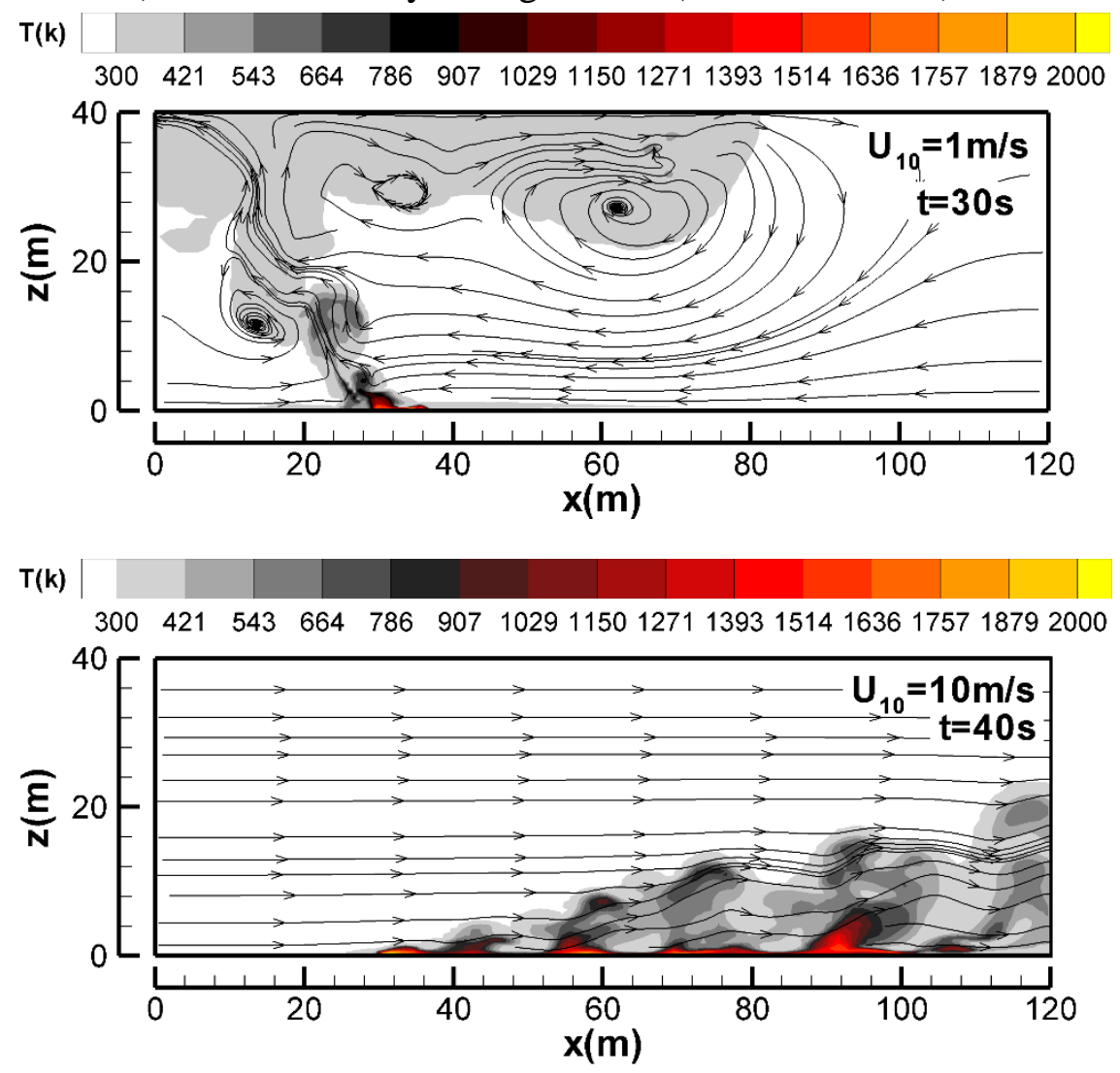

Figure 3 - Temperature field and streamlines of the gaseous phase, obtained in the vertical median plane $(y=$ $70 \mathrm{~m})$ for $U_{10}=1 \mathrm{~m} / \mathrm{s}($ top $)$ and $U_{10}=10 \mathrm{~m} / \mathrm{s}$ (bottom), corresponding to the 3D fields shown in Fig. 2. 

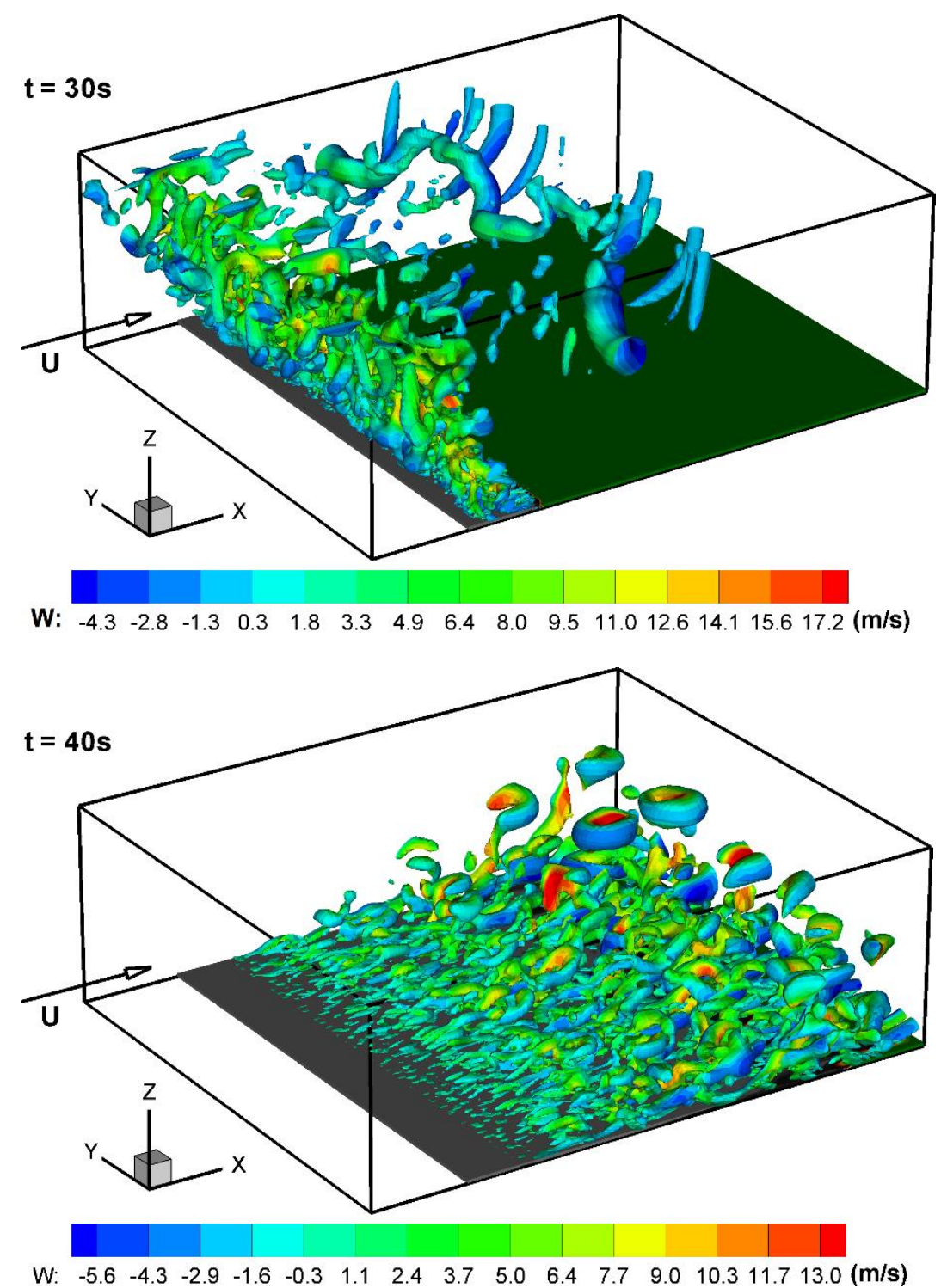

Figure 4 - Flow structure in a grassland fire for $U_{10}=1 \mathrm{~m} / \mathrm{s}$ (top) and $U_{10}=10 \mathrm{~m} / \mathrm{s}$ (bottom), shown using an isovalue surface of the $Q$ criterion $\left(Q=1 \mathrm{~s}^{-2}\right)$ colored by the vertical component $w$ of the velocity field, corresponding to the results shown in Figs. 2 and 3.

The Rate of Spread (ROS) of fire was estimated from the time derivative of the average position of the pyrolysis front at the surface of the vegetation cover, and shown in Fig. 5 versus with the 10-m open wind speed. The experimental data shown in Fig. 5 were obtained from Cheney and Gould, 1995, and Cheney et al, 1998, for different lengths $w$ of the ignition line. These experimental studies show that the ROS increases with $w$, as found by FIRETEC model predictions (16 m and $100 \mathrm{~m}$ ) (Linn and Cunningham, 2005), before reaching an asymptotic value for $w>200 \mathrm{~m}$. The relatively large dispersion of the experimental measurements can result from the unsteadiness nature of the wind flow (Morvan, 2014). On the other hand, the reported experimental data for $U_{10} \geq 8 \mathrm{~m} / \mathrm{s}$ (Cheney et al, 1998) were estimated from measurements recorded during real wildfires with significantly large fire front, but for which wind speed and vegetation characteristics are not under control as in experimental fires. For low to moderate $U_{10}$ values (up to $6 \mathrm{~m} / \mathrm{s}$ ), FireStar3D results compare well with experimental data and with other predictions, and we can observe a quasi-linear evolution of the ROS. For $\mathrm{U}_{10} \geq 8 \mathrm{~m} / \mathrm{s}$, the results are consistent with the predictions of other models (FIRETEC and WFDS) and with the experiments, despite the relative dispersion of the experimental measurements which prevents a significant comparison. 


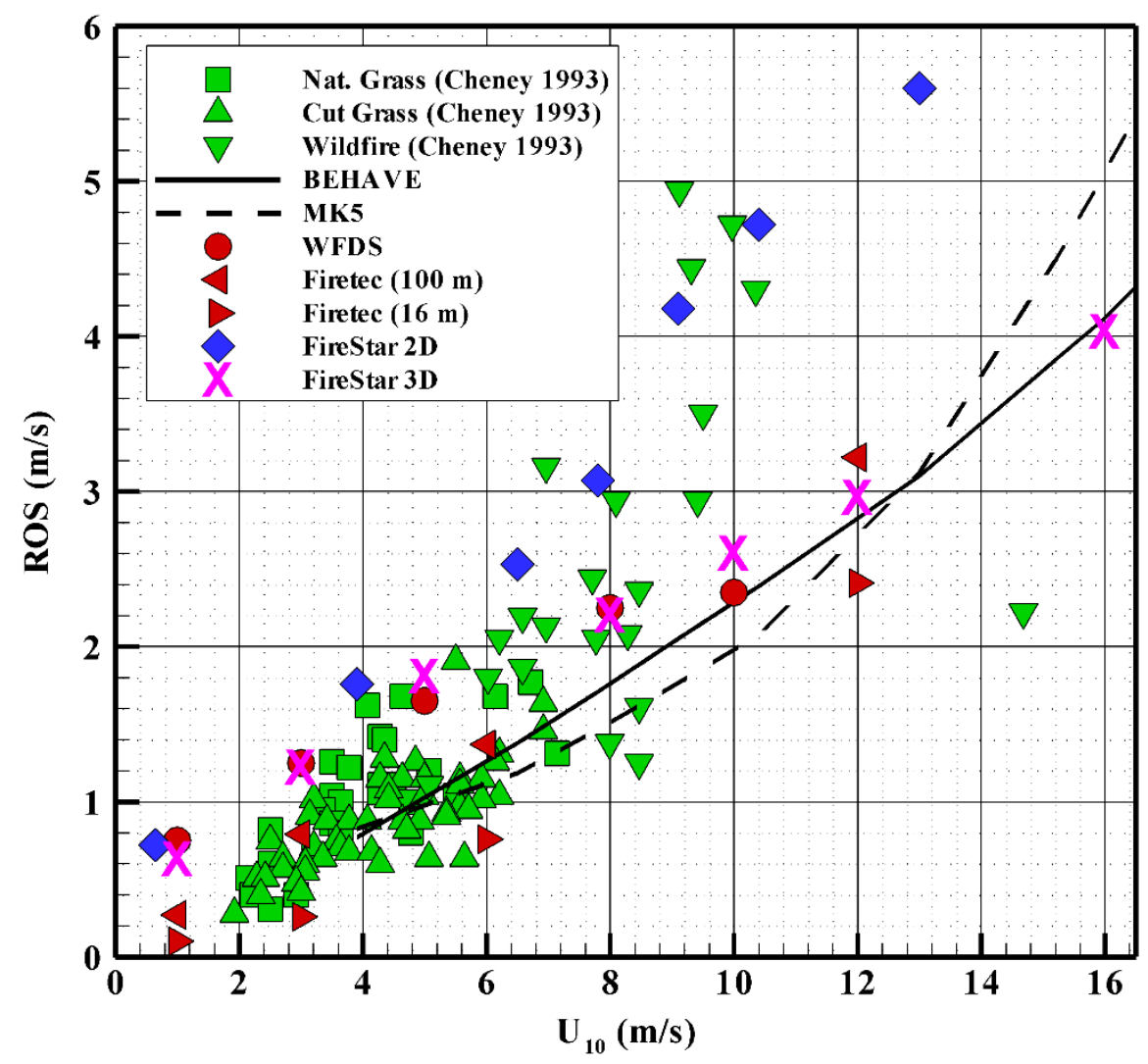

Figure 5 - Rate of fire spread (ROS) through a uniform grassland obtained for different 10-m open wind speeds. The results of FireStar3D are compared to those obtained experimentally by Cheney and Gould, 1995, and by Cheney et al, 1998, using the empirical model MK5 (McArthur, 1967), the semi-empirical model BEHAVE (Rothermel, 1972), $3 D$ numerical models FIRETEC (Linn and Cunningham, 2005) and WFDS (Mell et al, 2007), and the 2D numerical model FireStar2D (Morvan et al, 2009).

The fireline intensity $I_{B Y R}$ (Byram's intensity) can be evaluated from $I_{B Y R}=m \times \Delta H \times R O S$ (Byram, 1959), where $m=\alpha \rho \delta$ is the fuel load (equal to $0.7 \mathrm{~kg} / \mathrm{m}^{2}$ for the present study), and $\Delta H$ is the heat yield of the fuel. To avoid the uncertainty on the value of $\Delta H$, the heat release rate $H R R$ given by Eq. 1 was computed, where $\omega_{v a p}, \omega_{p y r}, \omega_{c h a r}, \omega_{C O}$ and $\omega_{\text {soot }}$ are respectivelly the total mass rates of water evaporation, pyrolysis, char combustion, combustion of $\mathrm{CO}$ in the gas mixture, and soot combustion, and $\Delta H_{v a p}, \Delta H_{p y r}, \Delta H_{\text {char }}, \Delta H_{C O}$ and $\Delta H_{\text {soot }}$ are the corresponding specific heats.

$$
H R R=-\omega_{\mathrm{vap}} \cdot \Delta H_{v a p}-\omega_{\mathrm{pyr}} \cdot \Delta H_{p y r}+\omega_{\text {char }} \cdot \Delta H_{\text {char }}+\omega_{C O} \cdot \Delta H_{C O}+\omega_{\text {soot }} \cdot \Delta H_{\text {soot }}
$$

Note that $\Delta H_{\text {char }}$ is not constant, it depends on the proportion of $\mathrm{CO}$ to $\mathrm{CO}_{2}$ produced during charcoal combustion (Morvan et al, 2018), it varies between $9 \mathrm{MJ} / \mathrm{kg}$ (for an incomplete combustion) and $30 \mathrm{MJ} / \mathrm{kg}$ (for a complete combustion).

The fireline intensity is then obtained from $I=H R R_{s s} / w$, where $H R R_{s s}$ is the average value of the heat release rate obtained at steady state and $w=100 \mathrm{~m}$ is the fireline width. As shown by Fig. 6, the present numerical results are compared with the predictions obtained using the operational models MK5 and BEHAVE and the predictions of the 2D numerical model FireStar2D; we have also reported some evaluations extracted from direct observations of prescribed and wildland fires on the field (Alexander and Fogarty, 2002). The transition between a high and a very high fire danger index corresponds to a fire intensity of $6 \mathrm{MW} / \mathrm{m}$. Almost all the results obtained using the present model (except $U_{10}=1 \mathrm{~m} / \mathrm{s}$ ) are located above this threshold value, which means that, even if the wind speed remains quite moderate, the fire can exhibit a very dangerous behavior because the fuel moisture content is very low $(5 \%)$. 


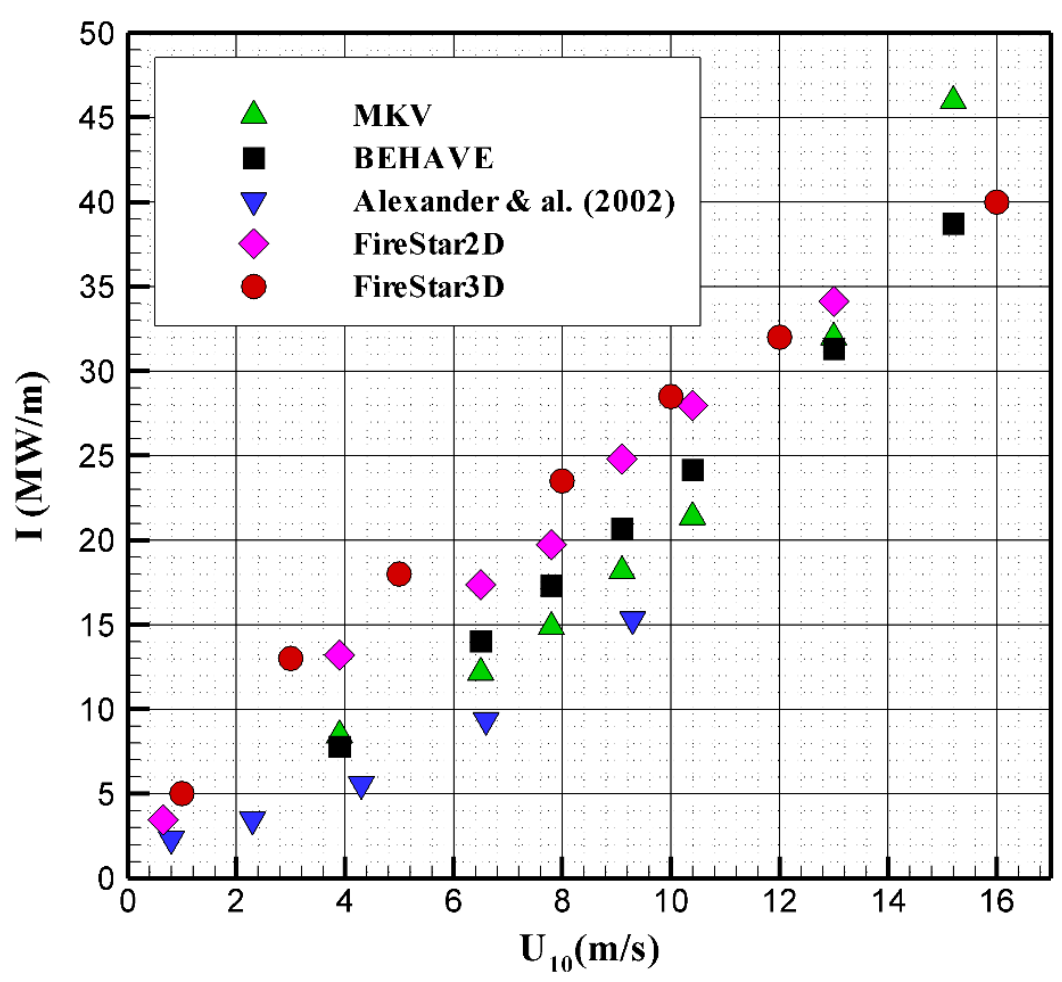

Figure 6 - Fireline intensity for fire propagation through a uniform grassland obtained for different 10-m open wind speeds. The results of FireStar3D are compared to those obtained experimentally by Alexander and Fogarty, 2002, using the empirical model MK5 (McArthur, 1967), the semi-empirical model BEHAVE (Rothermel, 1972), and the 2D numerical model FireStar2D (Morvan et al, 2009).

Finally, the heterogeneity of the fire front and its structuration as a succession of peaks and troughs is characterized by determining (using direct Fourier transform) the dominant wavelength of the temperature profile obtained along the transverse direction, $2 \mathrm{~m}$ above the fire front. This operation is performed during steady-state fire propagation and with a time interval of $1 \mathrm{~s}$. The wavelength $\lambda$ characterizing the fire front heterogeneity is then determined as the average value of the wavelengths obtained at different times. Froude's number based on the characteristic wave length $\lambda$, given by Eqs. 2 where $g$ is Earth gravity, is plotted in Fig. 7 versus Byram's convective number $N_{C}$ defined as the ratio between the buoyancy force and the inertial force due to the wind (Nelson, 2015) and given also by Eqs. 2, where $\rho_{0}$ and $C_{P 0}$ are the density and the specific heat of ambient air at temperature $T_{0}=300$ $\mathrm{K}$.

$$
F r=\frac{g \lambda}{\left(U_{10}-R O S\right)^{2}} \quad N c=\frac{\rho_{0} C_{P 0} T_{0}\left(U_{10}-R O S\right)^{3}}{2 g I}
$$

Large values of Byram's number are normally obtained in plume dominated fires, whereas small values of Byram's number are obtained in wind driven fires (Nelson, 2015). Figure 7 also shows the experimental results obtained by Finney et al, 2013, at laboratory scale in the case of flame spread in engineered cardboard fuelbeds; to our knowledge, these are the only available experimental data about the 3D structuration of the fire front. It was foreseeable to find that Froude's and Byram's numbers were well correlated with a certain exponent (equal here to 0.633 for the experimental data), since they both compare the ratio between the buoyant forces and the inertial forces. It was however interesting is to find that the correlations are almost the same at a small scale (experimental data) and at large scale (numerical results). 


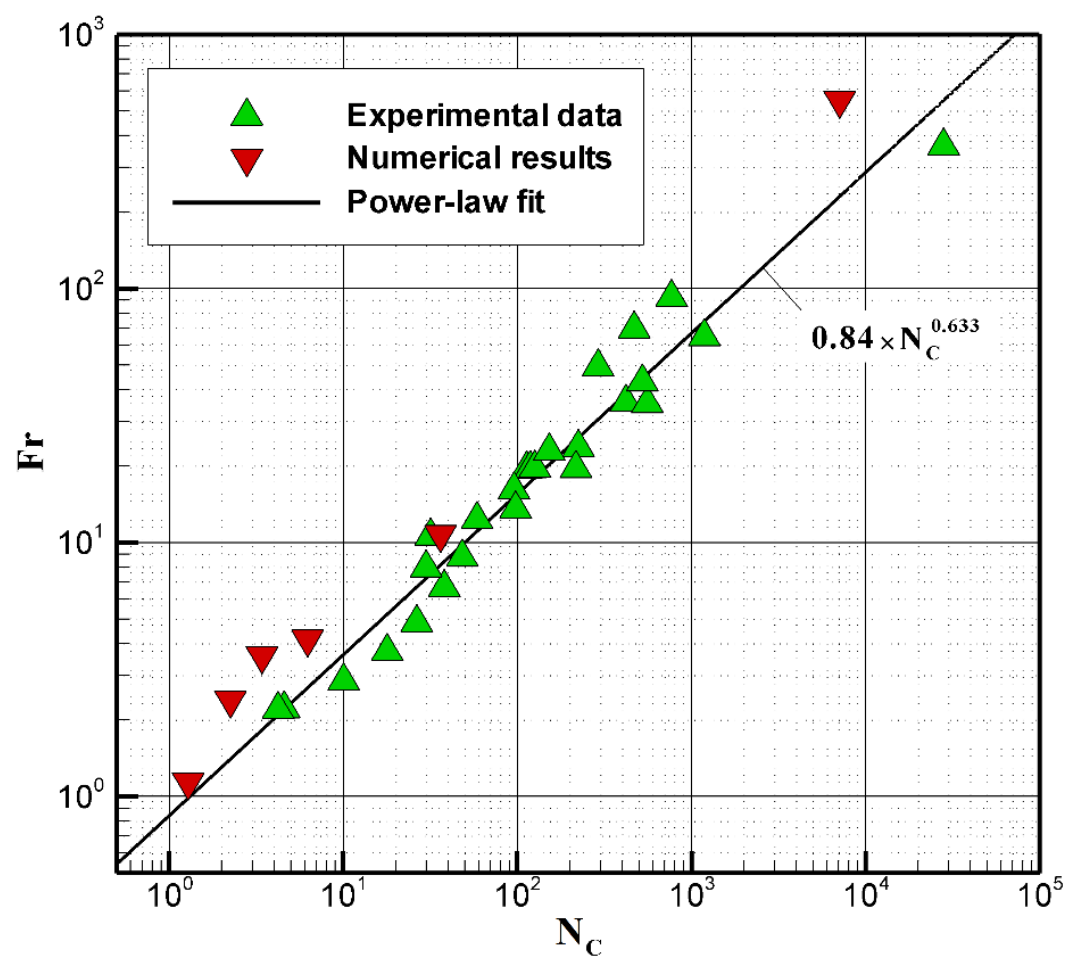

Figure 7 - Froude number based on the wavelength characterizing the fire front structure versus Byram's convective number. The results of FireStar3D obtained in the case of grassland fire are compared to those obtained experimentally at laboratory scale by Finney et al, 2013.

\section{Conclusions}

This study reported LES of fire spread of a quasi-infinite width fireline (obtained using periodic conditions at the lateral boundaries) through a homogeneous grassland. The results were obtained using a new 3D Computational Fluid Dynamic code based on a fully-physical multiphase model FireStar3D. The simulated Rate Of Spread of fire (ROS) and fire intensity were in good agreement with the data of the experimental campaign, with the predictions of operational empirical models (such as MK5 and BEHAVE), and with the numerical results of other 3D physical models (FIRETEC and WFDS). The simulations highlighted the effects of the wind speed on the ROS and on the intensity of fire, as well as the competition between the buoyant forces of the thermal plumes and the inertial forces of the wind. This competition is at the origin of the structuration of the fire front as a succession of peaks and troughs. Results also showed that the correlation between Froude's number (based on the fire-front structures characteristic-wavelength) and Byram's number is the same at small scale (litter fires) and at large scale (grassland fires). Many other fundamental aspects of the wildfire dynamic are not well understood, such as the role played by the field slope (and the competition between the wind and the slope when their directions are not aligned), the impact of the fuel moisture content (its threshold effect in the burn/no burn process, the linear or exponential decay of the rate of spread) ... In complement to experimental investigations, detailed physical models (such as FireStar3D) could be good tools for the understanding of the basic physical processes governing the behavior of wildfires.

\section{Acknowledgment}

The authors thank Aix-Marseille University for granting access to the HPC resources funded by Equip@ Meso project (ANR-10-EQPX-29-01) of "Investissements d'Avenir" program, as well as the Lebanese University for the financial support in the framework of the research-projects funding program. 


\section{References}

Alexander ME, Fogarty LG (2002) A pocket card for predicting fire behaviour in grasslands under severe burning conditions. Fire Technology Transfer Note 25.

Beer T (1991) The interaction of wind and fire. Boundary-Layer Meteorology 54, 287-308.

Byram GM (1959) Combustion of Forest Fuels. In K. P. Davis (Ed.), Forest Fire: Control and Use. (New York: McGraw Hill)

Canfield JM, Linn RR, Finney M, Forthhofer J (2014) A numerical investigation of the interplay fireline length geometry, and rate of spread. Agricultural and Forest Meteorology 189-190, 48-59.

Cheney NP, Gould JS, Catchpole WR (1998) Prediction of fire spread in grasslands, International Journal Wildland Fire 8, 1-13.

Cheney NP, Gould JS (1995) Fire growth in grassland fuels. International Journal of Wildland Fire 5(4), 237-247.

Cox G (1995) Combustion fundamentals of fire. (Academic Press: UK)

Finney MA (1998) FIRESITE: Fire Area Simulator-Model Development and Evaluation, Rocky Mountain Research Station Research Paper RMRS-RP-4. (Ogden, UT)

Finney MA, Cohen JD, Forthofer JM, McAllister SS, Gollner MJ, Gorham DJ, Saito K, Akafuah NK, Adam BA, English JD (2015) Role of buoyant flame dynamics in wildfire spread. Proceedings of the National Academy of Sciences 112, 9833-9838.

Finney MA, Forthhofer J, Grenfell IC, Adam BA, Akafuah NK, Saito K (2013) A study of flame spread in engineered cardboard fuelbeds, Part I: correlation and observations. $7^{\text {th }}$ International Symposium on Scale Modeling (ISSM-7), Hirosaki, Japan.

Frangieh N, Morvan D, Accary G, Méradji S, Bessonov O (2018) Numerical simulation of grassland fires behavior using an implicit physical multiphase model. Fire Safety Journal (available online 20 June 2018).

Grishin AM, Albini FA (Eds) (1997) Mathematical modeling of forest fires and new methods of fighting them. (Publishing House of the Tomsk University: Russia)

Hanson HP, Bradley MM, Bossert JE, Linn RR, Younker LW (2000) The potential and promise of physics-based wildfire simulation, Environmental Science \& Policy 3, 161-172

Hunt JC, Wray AA, Moin P (1988) Eddies, streams, and convergence zones in turbulent flows, In its Studying Turbulence Using Numerical Simulation Databases $2^{\text {nd }}$ Proceedings of the Summer Program, 193-208.

Incropera FP, DeWitt DP (1996) Fundamentals of Heat and Mass Transfer. (John Wiley and Sons: UK).

Kaplan CR, Bek SW, Oran ES, Ellzey JL (1994) Dynamics of a Strongly Radiating Insteady Ethylene Jet Diffusion Flame Combustion and Flame 96, 1-21.

Kee RJ, Rupley FM, Miller JA (1992) The Chemkin Thermodynamic Data Based. (Sandia National Laboratory)

Linn RR, Cunningham P (2005) Numerical simulations of grass fires using a coupled atmosphere-fire model: Basic fire behavior and dependence on wind speed. Journal of Geophysical Research 110, D13107.

Linn RR, Canfield JM, Cunningham P, Edminter C, Dupuy JL, Pimont F (2012) Using periodic line fires to gain a new perspective on multi-dimensional aspects of forward fire spread. Agricultural and Forest Meteorology 157, 60-76.

McArthur AG (1967) Fire behaviour in eucalypt forests, Forest Research Institute, Leaflet No. 107 (Canberra, Australia) 
Mell W, Jenkins MA, Gould J, Cheney P (2007) A physics-based approach to modelling grassland fires. International Journal Wildland Fire 16, 1-22.

Mell W, Manzello S, Maranghides A (2010) The Wildland-Urban Interface Problem - Current Approaches and Research Needs, International Journal Wildland Fire 19, 238.

Modest MF (2003) Radiative Heat Transfer. (Academic Press: UK)

Morvan D, Méradji S, Accary G (2009) Physical modelling of fire spread in Grasslands. Fire Safety Journal 44, 50-61.

Morvan D (2015) Numerical study of the behaviour of a surface fire propagating through a firebreak built in a Mediterranean shrub layer, Fire Safety Journal 71, 34-48.

Morvan D, Accary G, Meradji S, Frangieh N, Bessonov O (2018) A 3D physical model to study the behavior of vegetation fires at laboratory scale. Fire Safety Journal 101, 39-52.

Morvan D (2014) Wind Effects, Unsteady Behaviors, and Regimes of Propagation of Surface Fires in Open Field. Combustion Science and Technology 186, 869-888.

Nelson RM (2015) Re-analysis of wind and slope effects on flame characteristics of Mediterranean shrub fires. International Journal of Wildland Fire 24, 1001-1007.

Rothermel RC (1972) A mathematical model for predicting fire spread in wildland fuels, USDA Forest Service Research Paper 40 (INT, USA)

Sagaut P (2006) Large eddy simulation for incompressible flows: An introduction. (Springer-Verlag Berlin Heidelberg)

Sullivan AL (2009) Wildland surface fire spread modelling, 1990-2007. 1: Physical and quasiphysical models, International Journal of Wildland Fire 18, 349-368.

Syed KJ, Stewart CD, Moss JB (1991) Modelling soot formation and thermal radiation in buoyant turbulent diffusion flames. In $23^{\text {rd }}$ International Symposium on combustion (Pittsburgh), The Combustion Institute 23, 1533-1541.

Tolhurst KG, Shields B, Chong DM (2008) Phoenix: Development and Application of a Bushfire Risk Management Tool. Australian Journal of Emergency Management. 23, 47. 